\title{
Tourism as an Industry in Heritage Site-A Case Study on World Heritage Site of Fujian Tulou
}

\author{
Xiaomei Zhao \\ School of Architecture and Urban Planning, Beijing University of Civil Engineering and Architecture, Beijing 100044, China
}

\begin{abstract}
Cultural heritage is seen as a cultural capital. The heritage tourism increases the local employment and income, however, brings some problems at the same time, changing the traditional living way and industrial structure. The sustainability of economic development by tourism is also questioned. Fujian Tulou is a world heritage site in China, inscribed in 2008. The nomination has brought great changes to the sites, especially the flourishing tourism industries by the local communities as well as the tourism companies. The latter also take part in the management of the heritage site and get most of the income. The data in economic areas is analyzed in this study and explains the cultural tourism as a positive drive for the local economy, which contributes little to the life of locals. With the analysis of the changes and benefits from the tourism, we have found that tourism, as a dominant industry, might be a potential negative element for heritage conservation. According to the different situations of sites in Fujian Tulou, a proper planning of management is in need to integrate the tourism, conservation and development.
\end{abstract}

Key words: Tourism, industry, cultural heritage conservation, Fujian Tulou.

\section{Introduction}

Fujian Tulou is a world heritage site in China. Tulou means "earthen house" in Chinese, and it is a kind of vernacular architecture in southeastern China, especially in Fujian Province. Fujian Tulou is a particular type of communal living and defensive organization, known as "a little kingdom for the family" or "a bustling small city", which houses up to 800 people in one building.

The nominated buildings (Tulous) are located in ten villages or towns of three separate counties, belonging to two cities (Fig. 1). They are constituted of 46 buildings, of which some are single buildings while others are in clusters (Table 1). These houses were constructed between 15th to 20th century, of which four buildings were constructed in Ming dynasty (AD 1368-1644), 24 in Qing dynasty (AD 1644-1912), seven in Republic of China (1912-1949) and 11 after 1949 (Fig. 2). They were built by the Hakkas to

Corresponding author: Xiaomei Zhao, Ph.D., lecturer, research fields: conservation of cultural heritage and architectural history. E-mail: mayfishfish@gmail.com. defend their enemy, combined with the building traditions of the indigenous [1]. Tulous are of multi-story structure and inward-looking. Each building was built to house a large family, each core family of which lives in a vertical unit of the house. With the growth of population, this large family might build another Tulou, so built the relation of mother and son between these two houses.

The floor plan of Fujian Tulou is circular or square. The circular buildings are seen as a mature style which remedies the defects in structure of square buildings. Tulou could also be classified by the form of interior space. In some buildings, each core family has their own entrance and stair, while others share their transportation space with corridors linking all the household (Fig. 3). In the courtyard of the building, there might be some public buildings for all the residents, such as the ancestral hall, the school or the salon. Tulou and its environment function as the living, working and amusing places for the residents.

Fujian Tulou is not only an exceptional example of unique building traditions but also a living heritage interprets the local community culture. It presents a 


\section{Location Map of Fujian Tulou in Fujian Province}

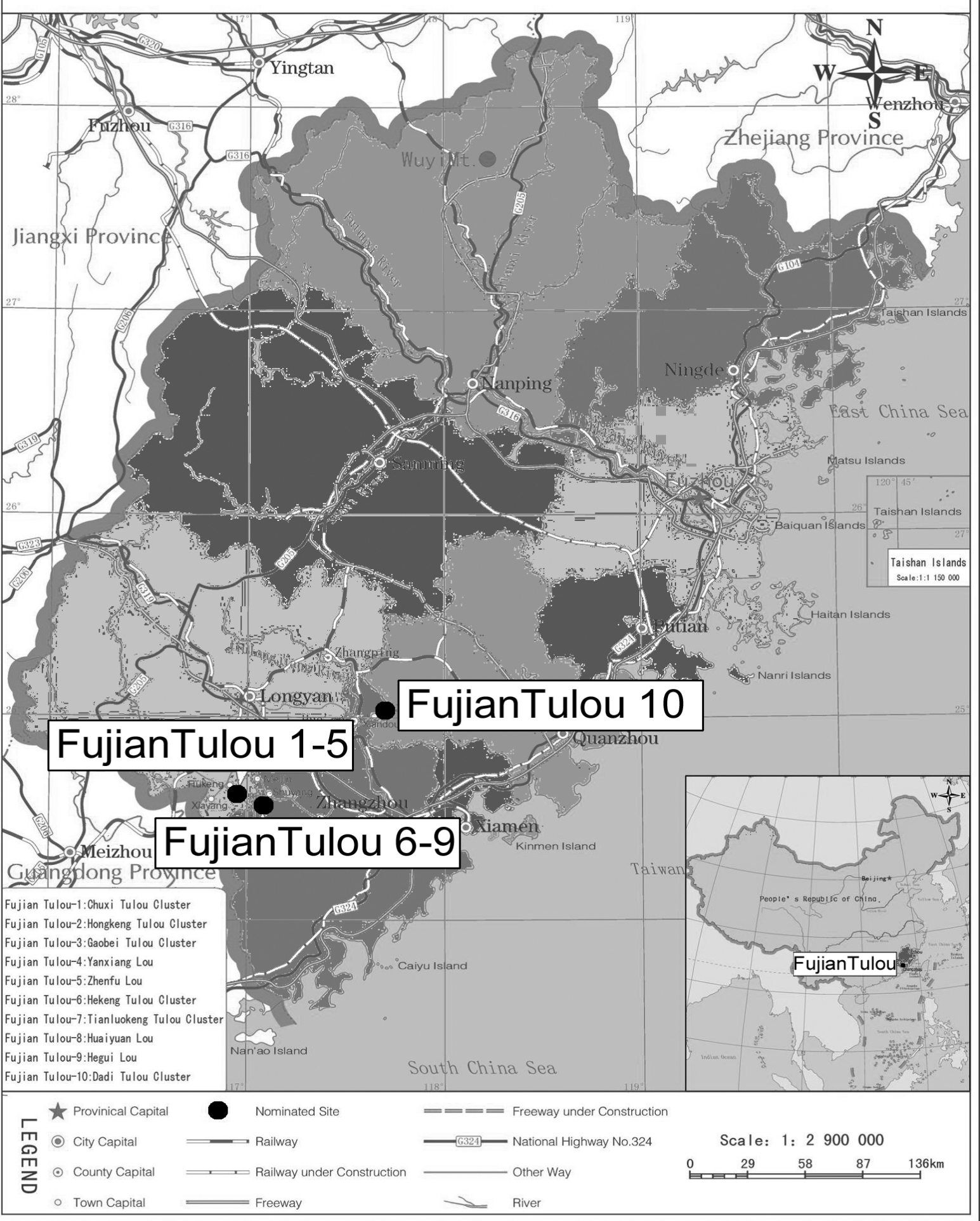

Fig. 1 Location map of Fujian Tulou.

Source: Nomination Documents of Fujian Tulou. 
Table 1 Fujian Tulou in the world heritage list.

\begin{tabular}{llllc}
\hline City & County & Name & Amount of buildings & Serial number \\
\hline \multirow{4}{*}{ Longyan } & \multirow{4}{*}{ Yongding } & Chuxi Tulou Cluster & 10 & 1 \\
& & Hongkeng Tulou Cluster & 7 & 2 \\
& & Gaobei Tulou Cluster & 4 & 3 \\
& & Yanxiang Lou & 1 & 4 \\
& & Zhengfu Lou & 1 & 5 \\
\hline \multirow{3}{*}{ Zhangzhou } & Hekeng Tulou Cluster & 13 & 6 \\
& \multirow{3}{*}{ Nanjing } & Tianluokeng Tulou Cluster & 5 & 7 \\
& & Huaiyuan Lou & 1 & 8 \\
& & Hegui Lou & 1 & 9 \\
\hline
\end{tabular}

farming culture in the mountain areas. The lineage organization keeps its power, unites the community and continues the local culture with the traditional faith of the ancestor worship. The local community plays a key role in the cultural continuity as well as the conservation of heritage, including the intangible traditions, the tangible buildings and their environment.

\section{Changes after Nomination}

Fujian Tulou was not well-known, and the local community kept their own pace of life, continued with their traditions. However, tourism has brought huge changes in the sites after nomination.

\subsection{Tourism Development after Nomination}

The title of "world heritage" has always been chased by tourists in and out of China. After

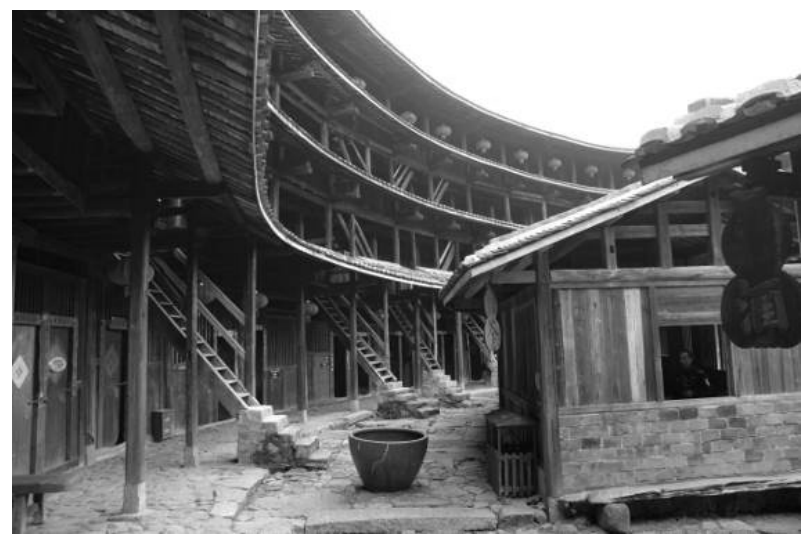

(a) Separate entrances and stairs for each family, Yuqing Lou in Chuxi Cluster nomination in 2008 , the number of tourists coming to the heritage sites of Fujian Tulou has increased dramatically (Fig. 4), which promoted the local tourism industries. The heritage tourism revenue has

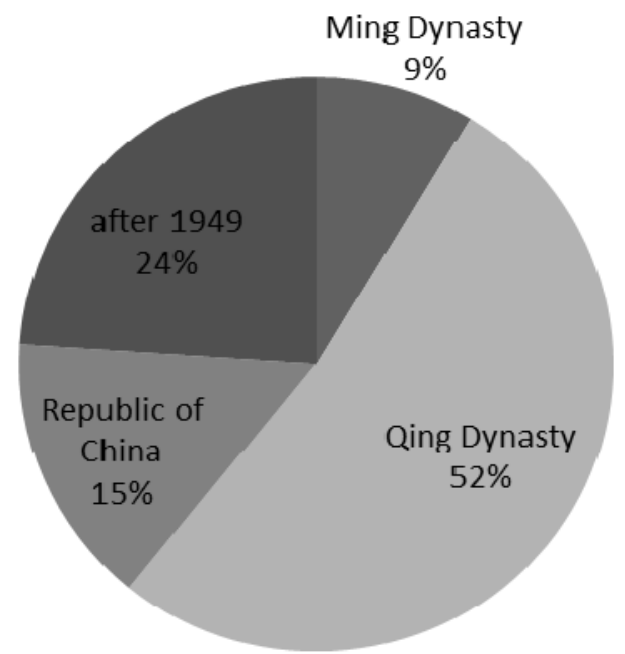

Fig. 2 Nominated buildings of Fujian Tulou in different periods.

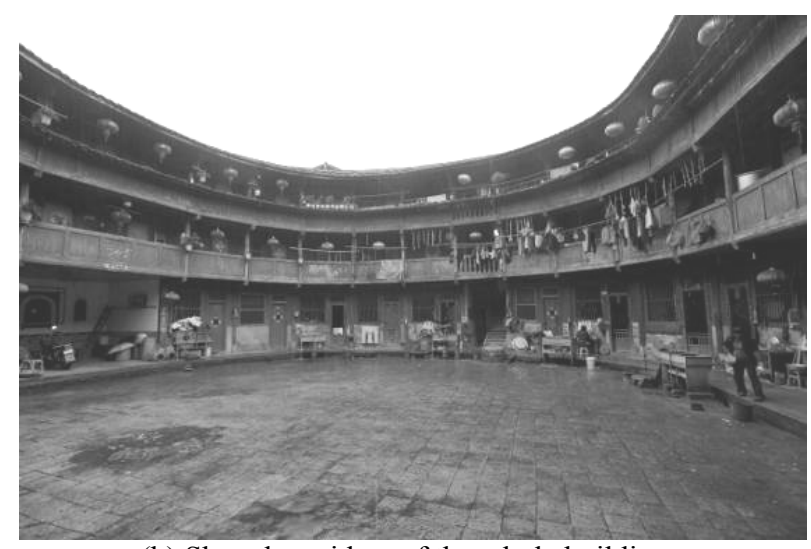

(b) Shared corridors of the whole buildings, Shanqing Lou in Chuxi Cluster

Fig. 3 Two different forms of interior space of Tulou (photo by Y. Jia, 2011). 


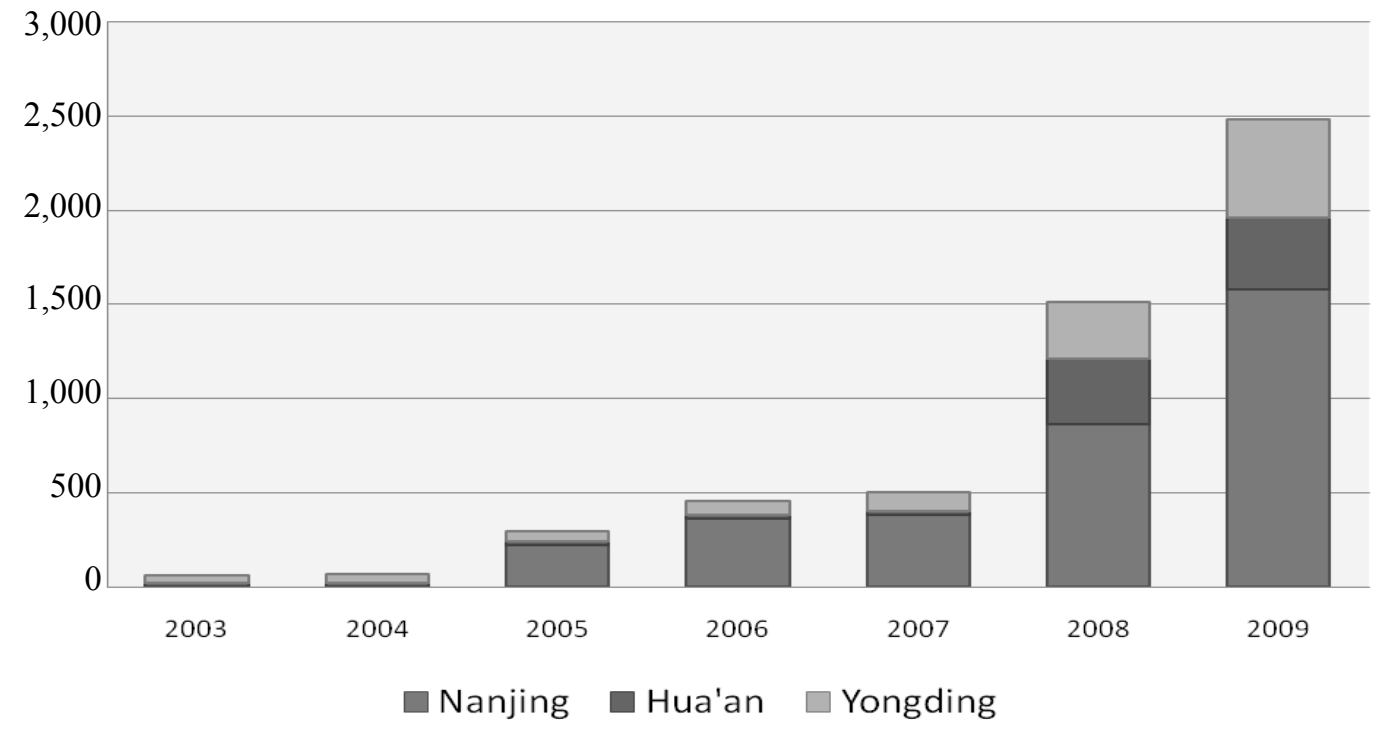

Fig. 4 Tourists to Fujian Tulou in 2003-2009 (thousands of people).

Source: Yongding Bureau of Cultural Relics, Nanjing County Yearbook, Hua'an Bureau of Culture and Sports.

increased and therefore contributed to the local GDP (gross domestic product). For example, the tourism revenue of Nanjing County in 2008 reached nearly four times as the previous year, and was $5.1 \%$ of the local GDP, tourism revenue of Hua' an Cluster was over 30 million RMB (around 4.4 million American dollars according to the prevailing exchange rate) in $2009,65.0 \%$ of the county's total revenue [2].

As a favorable factor for the local economy, the tourism is welcomed by the local government. Tourism companies are introduced to the heritage sites to manage the Tulou tourism together with the government and local community.

There are three independent management systems in the three counties where situated the nominated buildings. The 23 buildings of five villages or towns in Yongding County are managed by the Bureau of Culture Relics of Yongding Government and the Hakka Tulou Tourism Development Co, Ltd.. The 20 buildings of four villages or towns in Nanjing County are managed by the Site Management Committee, the Bureau of Culture of Nanjing Government and the tourism company. The three buildings in Dadi village in Hua'an County are managed by Municipal Bureau of Culture and Sport of Hua'an Government and the Tourism Development Company [2]. The governments and tourism companies (which also belong to the governments, except the tourism company in Hua'an County) make the major body of the management system, in which lacks the voice of the local community. The result is that it contributes more to the local economic indicators, not to the life of local residents, who is the core community of the heritage [3].

The management systems lead to different effects to the heritage sites, both in heritage conservation (including the intangible aspects) and tourism development, which will be talked in the following part. At the same time, there exist some conflicts between different counties in the tourism competition, especially between Nanjing and Yongding, which are close geographically. It is not good for the regional sustainable development.

\subsection{Changes in Local Industry Structure}

The local industry structure has been changing, caused by the development of heritage tourism. The tertiary sector (service occupations) has increased a lot and become a large part of the local industry structure in Yongding and Nanjing Counties; while in Hua' an it has no obvious change (Fig. 5).

The local community used to engage in farming, 


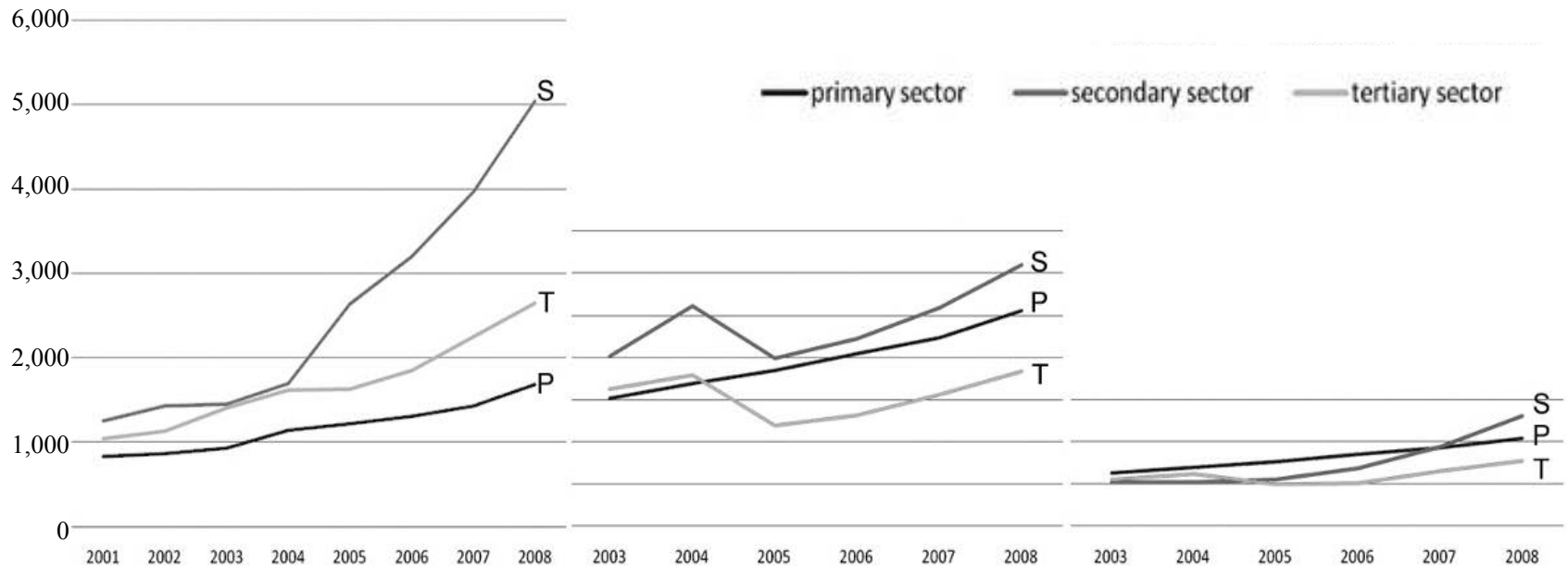
(a) Yongding County
(b) Nanjing County

(c) Hua'an County

Fig. 5 Industries changes in Nanjing, Hua'an and Yongding Counties.

Source: Research on Conservation of World Cultural Heritage and Economic Development of Heritage Sites.

supporting their life and shaping their culture. Tea producing was another important industry in the area, which was the main source of income and enriched the local culture as it provided more funds and opportunities to hold cultural events. These traditional industries, together with handicrafts and aquaculture, have been developing throughout the history, paying attention to the nature and getting the harmony between the built and natural environment.

New modes of productions have been developing ever since the society changed. Lots of Chinese in southeast of China went out to South Asia in the end of 19th century and the beginning of 20th century. This is a tradition for the people in Fujian Province. After 1980s, most young people flocked to developed cities in China for work, such as Guangzhou and Shenzhen, and the labor export became the main industry in many places. The dominant role of industry has turned to tourism industries in some places after 2008, but not all sites (Table 2). According to our field work and interviews, the management systems and development plans explain the diverse situations of different sites.

In general, tourism is developing in all sites and has become the dominant industries in the highlights of the sites (Table 3), such as Hongkeng in Yongding
County, Changjiao (Huaiyuan Lou and Hegui Lou) and Tianluokeng in Nanjing County. But Yanxiang Lou and Hekeng are two exceptions, the former has no residents living there, and young people all go out in the latter as no local industries could be continued due to the protection requirements of the nominated buildings.

\subsection{Changes in Living Way of Local Community}

The living way of local community has changed, and it could be seen as a result of the change of local industry structure. The changes differ a lot between sites. For example, there is little change in Dadi Tulou Cluster in Hua'an County and the community still mainly engages in tea producing. To the contrary, in Yongding and Nanjing, the living way changes greatly where new industries like labor export and tourism are booming up (Fig. 6).

The life changes a lot where tourism becomes the dominant industry. Take Hongkeng and Tianluokeng as examples. The local people used to go out of the town for living, but come back hometown to run some souvenir shops (or stalls), restaurants and inns now. This has brought both positive and passive consequences. For the good thing, more young people stay and have the opportunities to learn the local 
Table 2 Industries in the heritage sites of Fujian Tulou.

\begin{tabular}{lll}
\hline Industry & Development & Causes \\
\hline Traditional farming & Declining generally & $\begin{array}{l}\text { The local mountainous environment is not quite suitable for } \\
\text { farming; the farming does not take full use of labor and its } \\
\text { income is low; the farming land is used for tourism or } \\
\text { construction for new villages. }\end{array}$ \\
\hline Tea producing & $\begin{array}{l}\text { The local climate and environment is suitable for tea } \\
\text { cultivation; there has been mature technology and high } \\
\text { acceptance from the market; the income is high; the producing } \\
\text { conditions are met in the new villages. } \\
\text { It needs some funds; some processes of production are } \\
\text { forbidden in the nominated buildings but no new buildings to } \\
\text { replace the original production space. }\end{array}$ \\
\hline Traditional handicraft & Stopping in other areas & $\begin{array}{l}\text { The products do not meet the current needs; the traditional } \\
\text { crafts are not taken enough notice. }\end{array}$ \\
\hline Traditional aquaculture & Declining generally & $\begin{array}{l}\text { There are more accesses to the meat in the market economy; it } \\
\text { is forbidden in the nominated buildings. }\end{array}$ \\
\hline Labor export & Developing rapid in some areas & $\begin{array}{l}\text { There are traditions for the locals; there are not enough } \\
\text { employments in the local places, with surplus labor; the income } \\
\text { is high. } \\
\text { There are more local employments in tourism industries and its } \\
\text { income is as high as working outside. }\end{array}$ \\
\hline Tourism & Declining in other areas & $\begin{array}{l}\text { It increases the household income; there are some employments } \\
\text { in the tourism companies. }\end{array}$ \\
\hline
\end{tabular}

Table 3 Dominant industries in the heritage sites of Fujian Tulou.

\begin{tabular}{llll}
\hline County & Sites & Dominant industry/industries & Other industries \\
\hline \multirow{4}{*}{ Yongding } & Chuxi (Cluster) & Labor export & Tourism, farming, tea producing \\
& Hongkeng (Cluster) & Tourism, labor export & Farming, tea producing \\
& Gaobei (Cluster) & Labor export & Tourism, farming, tea producing \\
& Yanxiang Lou & Labor export & Farming \\
& Zhengfu Lou & Labor export & Tourism, farming, tea producing \\
\hline \multirow{3}{*}{ Nanjing } & Hekeng (Cluster) & Labor export & Farming \\
& Tianluokeng (Cluster) & Tourism & Tea producing, labor export, farming \\
& Changjiao (Huaiyuan Lou \& Hegui Lou) & Tourism, tea producing & Labor export, farming \\
\hline Hua'an & Dadi (Cluster) & Tea producing & Tourism, farming \\
\hline
\end{tabular}

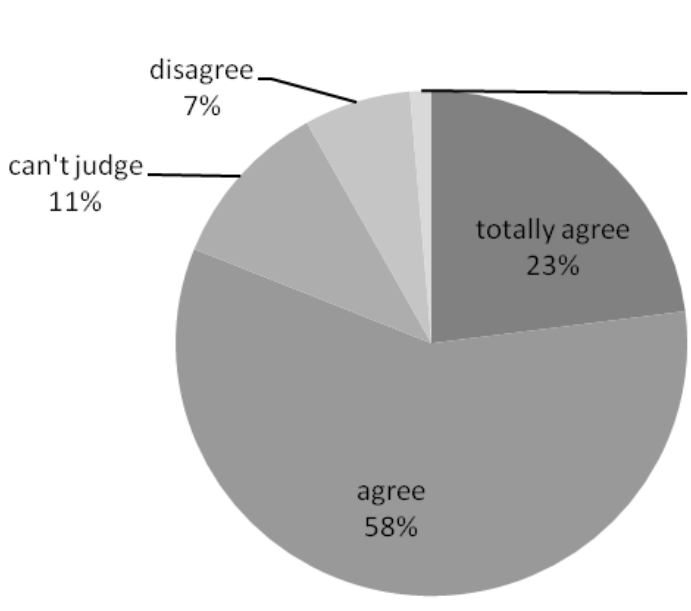

(a) Yongding County

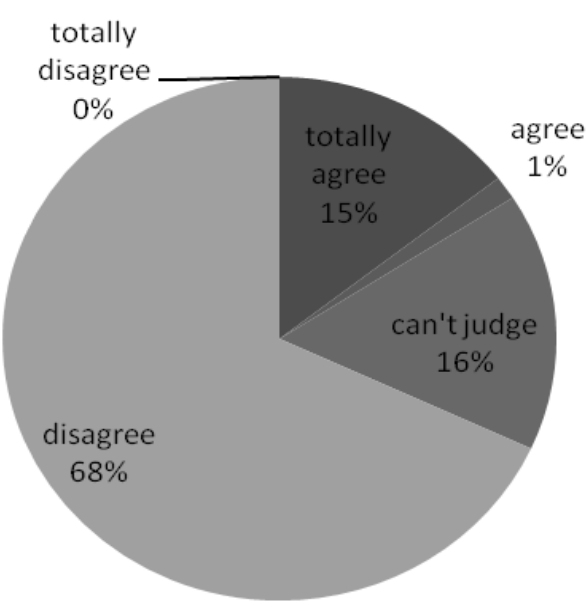

(b) Hua'an County

Fig. 6 Statistical results from the questionnaire on "Do you think your life style has greatly changed after the world heritage site nomination?".

Source: Research on conservation of world cultural heritage and economic development of heritage sites. 
tradition, which was impossible when they were all out, and the sites turn to be more "living". For the not so good, too many souvenir shops or stalls and restaurants give inauthentic feelings to the heritage sites (Fig. 7), not only because they are not coordinating with the heritage buildings, the products they sell lack the local traits, but also because the community now seems to live quite a different life than before.

However, even in the famous sites, the traditional life keeps on parallel with the new tourism industries. We did a statistics of local people's behavior in Hongkeng, where we counted the numbers of people who were engaging in traditional industries such as farming or tea producing and who were engaging in tourism industries, and the result showed that they balanced (Fig. 8).

The heritage tourism has enhanced the cultural identity and proud of the local community, but at the same time lead to inconvenience to their daily life. "Some strangers come into our house" is an often-heard complaint from the local residents, and it causes stealing. As all the sites require an admission tickets to the tourists, people from neighboring villages or towns who want to visit their friends and relatives have difficulties to just walk into the "heritage areas".

The heritage protection has the same "double-edged" problems. All the residents agreed that the protection measures brought improvement in their living conditions, but some activities would no longer be possible in their own houses, for example

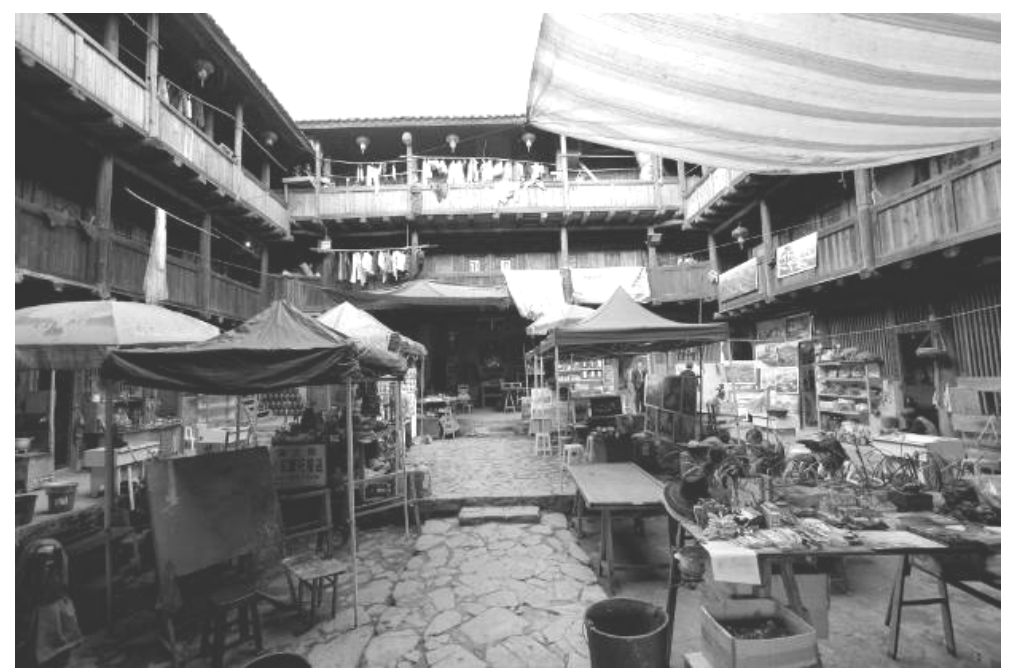

Fig. 7 Souvenir stalls in the courtyard of nominated Tulou in Tianluokeng Cluster (photo by Y. Jia, 2011).

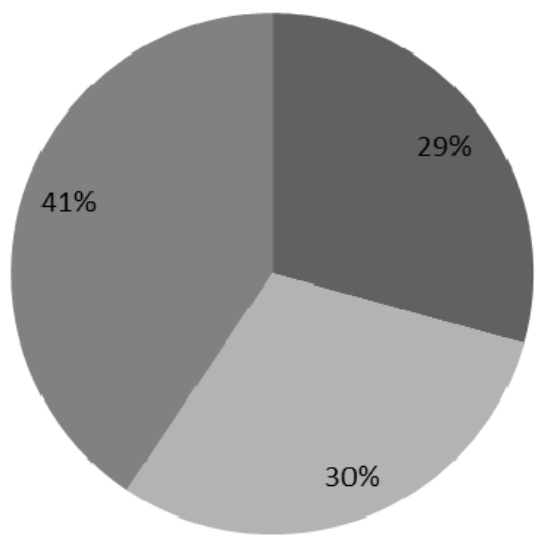

- engaging in traditional industries

- engaging in tourism industries

- others(resting, etc.)

Fig. 8 The amount of people's different behavior. 
the tea producing, which might cause damages to the buildings. In Dadi village, new dwellings were built for the tea makers so that they could keep their production and it was also good for the buildings as not too many residents to live in the nominated houses. However, no new residential buildings were built for the residents of Yanxiang Lou and Hekeng Tulou Cluster, where the locals have to go out for a living. They could not produce tea in their houses as it is against the conservation demand. As a result, there are almost no young people in the village and their cultural continuity is facing great crisis. The sites are clean and beautiful (Fig. 9), as a museum, not a living heritage site.

\section{Benefit from Tourism for the Local Community}

Obviously, the tourism has brought great benefit to local economy indicators, but is there some benefit to the local community?

\subsection{Community's Income from Tourism Companies}

The admission tickets make a large part of the economic contributions from heritage tourism. The ticket income is obtained by the tourism companies who manage the tourism, build some facilities and offer guided tours. Actually, they utilize the heritage resource and they ought to pay for this to the owners of the heritage - the local community.

The buildings in the heritage sites could be classified into nominated Tulou and non-nominated, whose owners get different income from the tourism companies. For most sites, there are two kinds of income. The rent means the money for the owners of nominated buildings and it is distributed to the household according to the area of the buildings. The resource fee means the money for all the villagers, distributed according to the population. For the sites of clusters where almost all of the buildings are nominated, like Nanluokeng and Hekeng, the rent and the resource fee are similar and paid to each person in the villages. For the single buildings, there might be no resource fee for the villagers. The income distinguishes a lot in different sites (Table 4). All these incomes are fixed except Dadi cluster.

This kind of income is really little when each family gets only 2,000 RMB (about 309.7 American dollars, according to the average exchange rate in 2010, as the data was of the same year) per year for most and they have to bare all the inconvenience from tourism every day. The large part of tourism income comes into the companies, who are not the owner of the heritage. That is how the local think and it is not surprising that there are conflicts between the two.

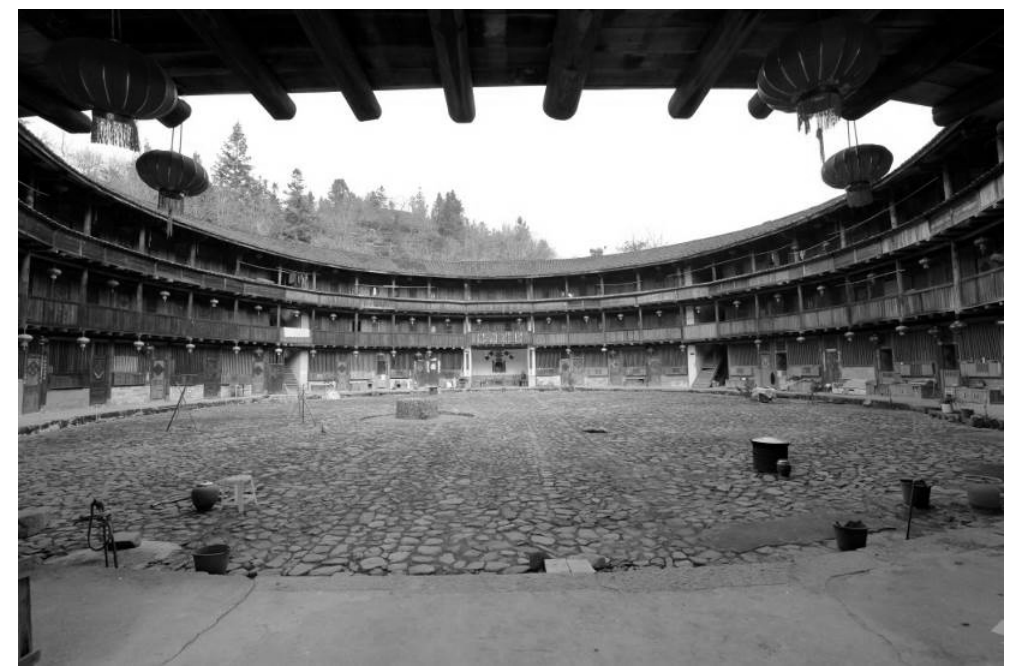

Fig. 9 Tulou lack of community's living life in Hekeng Cluster (photo by Y. Jia, 2011). 
Table 4 The earnings of locals in the heritage sites of Fujian Tulou (the values are calculated into American dollars according to the average exchange rate in 2010 , as the data was of the same year).

\begin{tabular}{|c|c|c|c|}
\hline County & Name & Rent (nominated Tulou) & Resource fee (village) \\
\hline \multirow{6}{*}{ Yongding } & Chuxi Tulou Cluster & $\begin{array}{l}\text { ¥30 (\$4.4) for each room per year (only Yuqing } \\
\text { Lou which is used as a museum); }\end{array}$ & $\begin{array}{l}\text { Insurance of } ¥ 2.8(\$ 0.4) \text { for } \\
\text { each person per year }\end{array}$ \\
\hline & & $¥ 100,000(\$ 14,772.1)$ per year for Zhencheng Lou, & $¥ 700-800(\$ 103.4-118.2)$ \\
\hline & Hongkeng Tulou Cluster & $\begin{array}{l}Y 40,000 \text { ( } \$ 5,908.9 \text { ) per year for Fuyu Lou, a couple } \\
\text { of thousands per year for other nominated buildings; }\end{array}$ & $\begin{array}{l}\text { for each person per year } \\
(2010)\end{array}$ \\
\hline & Gaobei Tulou Cluster & $\begin{array}{l}¥ 100,000(\$ 14,772.1) \text { per year for Chengqi Lou, } \\
¥ 30,000-40,000(\$ 4,431.6-5,908.9) \text { per year for } \\
\text { Shize Lou; }\end{array}$ & $\begin{array}{l}8.3 \% \text { of the ticket sales (not } \\
\text { implemented yet) }\end{array}$ \\
\hline & Yanxiang Lou & $¥ 20,000(\$ 2,954.4)$ per year; & None \\
\hline & Zhengfu Lou & $¥ 8,000(\$ 1,181.8)$ per year. & None \\
\hline \multirow{4}{*}{ Nanjing } & Hekeng Tulou Cluster & $¥ 22.9(\$ 3.4)$ for each room per year & None \\
\hline & Tianluokeng Tulou Cluster & None & $\begin{array}{l}¥ 150,000(\$ 22,158.2) \text { per } \\
\text { year for the whole village }\end{array}$ \\
\hline & Huaiyuan Lou & $¥ 20,000(\$ 2,954.4)$ per year & None \\
\hline & Hegui Lou & $¥ 25,000(\$ 3,693.0)$ per year & None \\
\hline Hua'an & Dadi Tulou Cluster & $\begin{array}{l}3.5 \% \text { of the ticket sales ( } ¥ 91,000 \text { in } 2010 \text {, i.e., } \\
\$ 13,442.6 \text { ) }\end{array}$ & $\begin{array}{l}0.5 \% \text { of the ticket sales } \\
\text { ( } ¥ 13,000 \text { in } 2010 \text {, i.e. } \\
\$ 1,920.3 \text { ) }\end{array}$ \\
\hline
\end{tabular}

\subsection{Other Benefits from Tourism}

Tourism is welcomed by the local people as other benefits are also brought in, such as the jobs offered by tourism companies and the income from running a family business. According to our interviews, most locals considered tourism as a good way to increase their income.

The owners of nominated buildings could run a small inn which attracts tourists to experience living in Tulou, as well as selling tea and some souvenirs. The residents close to the nominated buildings could run a restaurant which is forbidden in the nominated buildings or an inn with lower price. They might also rent their houses to people from outside of the sites who want to earn a living by selling paintings of Tulou. Others might sell their vegetable to the restaurant runners to get an additional income. The residents from nearby villages and towns could work for the tourism companies or benefit from their own family business as more tourists come and consume.

\subsection{Problems in Tourism and Their Solutions}

The previous studies show that tourism is an industry depending too much on outside [4]. It is quite seasonal in the cases in China, and the number of tourists surges during the Labor Day's and National Day's holidays. This means tourism industries could not be the sole dominant industry, otherwise there might be social problems. It might happen that the tourism decline generally or suddenly years later when huge quantity of labors would lose their jobs. Other industries, especially the traditional industries, should be encouraged and developed to ensure a steady economy and sustainable society.

Tourism without proper management might harm the spirit of heritage sites. In most sites of Fujian Tulou, there have been too many individual businesses without appropriate forms. Though the stalls are temporary and do not damage the buildings, they do harm the atmosphere. It leads the loss of authenticity. This could be solved by standardizing the souvenir stalls and more importantly, by encouraging the local community to engage in traditional industries, like tea producing, which might reduce the number of sellers.

The lack of regional planning is another existing problem in Fujian Tulou. The management systems of the three counties never thought to cooperate with each other and in fact they are competitors in tourism 
service. Even in the same county, there might be conflicts between people of the nominated sites and their neighborhood, where the former consider them as the supposed beneficiary but the latter might get more as they have no restrictions on construction. Harmony only exists in the same village or town, where people live and work together. A regional planning is in emergent need, not only on conservation but also on tourism, so that the benefit could be shared by all the people in and around the heritage sites.

Dadi Cluster sets a good example for other sites. Tea producing is still the dominant industry. The locals would not take tourism for more than normal importance and consider it only as an avocation besides tea producing. The allocation of profit is more fair and actually the community does not care much on how much they get from tourism as they have a more stable and high-income job as a tea planter and producer.

\section{Conclusions}

Fujian Tulou is a living heritage and the continuity of community's life is very important in conservation. The title of "world heritage" has brought some opportunities, and great changes have taken place after nomination, including the community's life and the industry structure, where the tourism plays a key role. Tourism is a good way to enhance the community's cultural consciousness and improve their living conditions, when cultural exchanges happen in tourism and the individual business increases their income. But it does not happen in all sites of Fujian Tulou.

Obviously, tourism has its advantages in developing the local economic. However, the locals might get little benefit as they are not considered as one of the managers of heritage tourism. At the same time, tourism industries could never replace of the traditional industries to become the sole dominant industry, owing to the inherent weakness. Diverse industries in the local industry structure are indispensable for the heritage sites.

There exist both good and bad situations of local society and heritage conservation in the case of Fujian Tulou. Tourism, as an essential factor to interpret the different results, needs to be properly managed, according to the current development for each site and be included in a master plan integrating all sites.

\section{References}

[1] H. Huang, Fujian Tulou: Treasure of Chinese Traditional Houses, Joint Publishing, Beijing, 2009.

[2] National Heritage Center, Research on Conservation of World Cultural Heritage and Economic Development of Heritage Sites, Beijing, 2011.

[3] B. Baillie, Living Heritage Approach Handbook, International Centre for the Study of the Preservation and Restoration of Cultural Property (ICCROM), Rome, 2009.

[4] T. Jimura, The impact of world heritage site designation on local communities - A case study of Ogimachi, Shirakawa-mura, Japan, Tourism Management 32 (2) (2011) 288-296. 